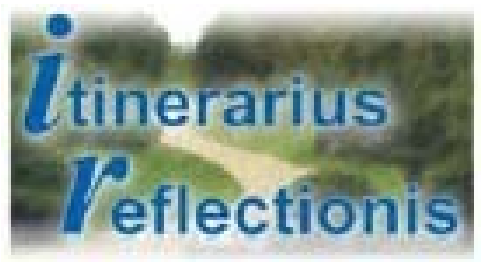

Revista Eletrônica de Educação do Curso de Pedagogia do Campus Jataí da Universidade Federal de Goiás

[Vol I - n.4 ] [jan/jul] [ 2008]

\title{
CULTURA E SEMICULTURA EM ADORNO
}

PINTO, Suely Lima de Assis. Mestre em Educação Brasileira - FE/UFG. Doutoranda em História - FCHF/UFG, professora do Curso de Pedagogia, Campus Jataí/UFG.

\section{RESUMO}

A educação e a formação humana são questões que permeiam grande parte dos debates acadêmicos atualmente. A formação diz respeito a um indivíduo livre, consciente de si mesmo e de sua cultura, que atua na sociedade por meio dessa consciência e em coletividade. Para Adorno é preciso educar para ler imagens de forma crítica, educar para ver televisão, para confrontar-se com a mídia, com a propaganda, com o mundo na sociedade capitalista, absolutamente ideologizado. Ao se refletir sobre a ideologia contida na cultura e na arte compreende-se que na indústria cultural não há processo formativo, há semiformação. Somente um sujeito universal, autônomo, estaria livre da barbárie - é preciso buscar a condição humana, pois somente quando se instaura a condição humana se instaura a civilização, a cultura, a formação humana.

\section{ASTRACT}

The education and the human formation are questions that penetrate big part of the academic debates nowadays. The formation is about a free individual, conscious of itself and its culture, that acts in the society by means of that conscience and in community. According to Adorno its necessary to educate to read images in a critical way, educate to watch $\mathrm{TV}$, to confront itself with the media, with the publicity, with the world in the capitalist society, absolutely ideologized. Meditating about the ideology inside the culture and art we can understand that in the cultural industry there is no formative process, there is semi-formation. Only a universal subject, autonomous, would be free of the barbarism - it's necessary to seek the human condition, as only when it establishes the human condition it establishes the civilization, the culture, the human formation.

Theodor Adorno em sua produção científica analisa o quanto a formação humana é incompleta, calcada na barbárie e impregnada por conceitos ideológicos em conseqüência de uma simplificação ou redução do conhecimento. Analisando por este ponto de vista, Martin Jay (1988) 


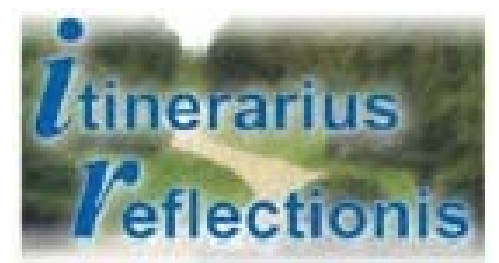

Revista Eletrônica de Educação do Curso de Pedagogia
do Campus Jataí da Universidade Federal de Goiás
[Vol I - n.4 ] [jan/jul] [ 2008]
ISSN: 1807-9342

diz que Adorno sempre foi cauteloso com a simplificação do pensamento filosófico reformulado para uma linguagem mais acessível ao cotidiano. Percebe-se, então, que debruçar sobre a obra de Adorno para compreensão do seu pensamento não é tarefa fácil - não se esquecendo também, das limitações que seus tradutores apontam sobre a própria tradução. Com base nos argumentos de Martin Jay (1988), acredita-se na dificuldade de expor com fidelidade o pensamento de Adorno que, para alguns tradutores, apresenta-se como intraduzível. Ou seja, ratifica-se a preocupação em não simplificar o pensamento filosófico, como o próprio Adorno alertou no texto 'Teoria da semicultura' (2002). Ao analisar a publicação de textos filosóficos importantes do passado, em edições de bolso, Adorno (2002) afirma que

seria insensato querer segregar tais textos em edições científicas, em edições reduzidas e custosas, quando o estado da técnica e o interesse econômico convergem para a produção massiva. Isso não significa, porém, que se deva ficar cego, por medo do inevitável, diante de suas implicações, nem, sobretudo, diante do fato de que entra em contradição com as pretensões imanentes de democratizar a formação cultural. Somente uma concepção linear e inquebrantável do progresso espiritual planeja com negligência sobre o conteúdo qualitativo da formação que se socializa como semiformação (ADORNO, 2002, p.12).

Ele considera a semiformação como uma ambigüidade do progresso em plena totalidade repressiva e a reprodução neste contexto, conforme seu próprio pensamento, não deixa de contribuir com uma semiformação.

A compreensão do pensamento de Adorno se instaura em uma seqüência de temas entrelaçados por uma mesma lógica. A arte, a família, a indústria cultural, a cultura, a formação humana, a psicanálise, a personalidade autoritária, o anti-semitismo, são categorias que vão sendo delineadas por uma mesma razão, a razão instrumental. É possível para Adorno percorrer estes diferentes temas porque, a razão que em sua origem deveria ser para libertar, se converte, ela própria em instrumento a serviço do indivíduo e da sociedade. O núcleo comum de seu pensamento é a razão instrumental e a generalização desta razão vai unificar todas as esferas. A cultura, dentre as categorias por ele elaboradas, apresenta-se em quase todos os seus textos, é uma das categorias que se converte nesta razão instrumental e que se transforma em ideologia. 


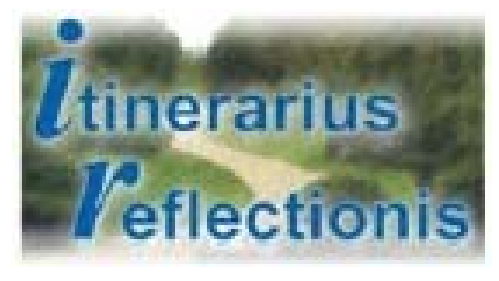

Revista Eletrônica de Educação do Curso de Pedagogia do Campus Jataí da Universidade Federal de Goiás

[Vol I - n.4 ] [jan/jul] [ 2008]

\section{Sobre o conceito de cultura}

Adorno, na concepção de Martin Jay (1988), foi um dos filósofos que mais contribuiu com a compreensão da cultura e, na base de seu interesse pelo conceito mais amplo de cultura, estava sua insistência no inevitável entrelaçamento entre a realidade material e a realidade ideal ou espiritual. Essa dualidade no conceito de cultura que Martin Jay (1988) aponta no pensamento de Adorno foi debatida pelo próprio Adorno e por Horkheimer no texto "Cultura e civilização", presente no livro Temas Básicos da Sociologia (1973).

Adorno e Horkheimer (1973) ressaltam que a nossa moderna civilização técnica tem produzido inúmeros fenômenos de massa e por isso, na sociedade moderna, a técnica adquiriu uma estrutura e uma posição específica, extremamente relacionada com as necessidades dos homens. Inicialmente a preocupação dos autores foi demonstrar que a cultura, neste contexto, sempre apresentou, uma conotação de cultura espiritual; e a civilização, uma conotação de progresso material. No entanto, neste texto, Adorno e Horkheimer (1973) demonstram que estas duas posições, na realidade, são intrínsecas entre si e não devem ser vistas de forma independente. Para eles, civilização não se opõe a cultura do espírito para caracterizar-se apenas como cultura material; ela, antes de tudo, designa o âmbito geral da humanidade, da civilização humana.

A conotação moderna do termo civilização, segundo estes autores, só aparece no século XIX e, a partir deste período, civilização passa a se relacionar com o aumento da população; após a Revolução Industrial, este termo também é relacionado com a concentração urbana. Para eles, somente uma consciência cultural, que não tendo a esperança de dar a humanidade à forma de liberdade e consciência, pode chegar a esta separação rigorosa entre cultura, como produto e forma da alma, e civilização, como exterioridade. Diante desta questão e na perspectiva de delinear uma não separação para os termos civilização e cultura, Adorno e Horkheimer (1973) apresentam o conceito de cultura e de civilização elaborado por Freud. 
Segundo eles, Freud, ao falar da cultura humana, se abstém dessa distinção entre cultura e civilização e diz que a cultura "por um lado, abrange todo o saber e capacidade que os homens adquiriram para dominar as forças da natureza e obter os bens que satisfazem as necessidades humanas; e por outro lado, todas as instituições necessárias para reger as relações dos homens entre si e, novamente, a distribuição dos bens obtidos". (Freud ${ }^{1}$ apud: ADORNO E HORKHEIMER, 1973, p. 97). É neste sentido que Adorno e Horkheimer (1973) reforçam que civilização e cultura não devem ser postas uma contra a outra, pois, na verdade, a atividade civilizatória, como produção e uso de recursos instrumentais, tem sido hoje intolerável a si própria. Por meio desse processo técnico, cultura se transformou em indústria cultural e os homens idiotizados giram em torno do consumo e produção de bens. Instaura-se então, uma tensão entre cultura e ideologia, e a realidade apresentada aos homens torna-se falsa.

Adorno, no texto "Crítica cultural e sociedade" (1998), explora as condições ideológicas em que se encontra a cultura e como a crítica é inoperante ao lidar com seu objeto de conhecimento. Nesta lógica a crítica é apenas adesão. No escopo da expressão crítica cultural, está presente uma flagrante contradição que se apresenta, entre o crítico e seu objeto de análise. $\mathrm{O}$ crítico fala como se fosse o representante de uma natureza imaculada ou de um estágio histórico superior, no entanto, diz Adorno (1998), ele é da mesma essência daquilo que acredita estar subjugado a seus pés. "A insuficiência do sujeito que pretende, em sua contingência e limitação julgar a violência do existente (...) torna-se insuportável quando o próprio sujeito é mediado até a sua composição mais íntima pelo conceito ao qual se contrapõe como se fosse independente e soberano" (ADORNO, 1998, p. 7).

A racionalidade na qual o crítico trabalha é a mesma em que ele acredita e por isso não é possível seu distanciamento do objeto de sua crítica. Quando ele analisa determinado produto cultural, a lógica de construção de seu pensamento opera na mesma lógica de construção do produto cultural analisado. Muitas vezes, diz Adorno (1998), o crítico encerra aos leitores uma

${ }^{1}$ FREUD, Sigmund. O Futuro de uma Ilusão. Tradução de José Otávio de Aguiar Abreu. Rio de Janeiro: Imago, 1997. Apud: Adorno e Horkheimer (1973). 


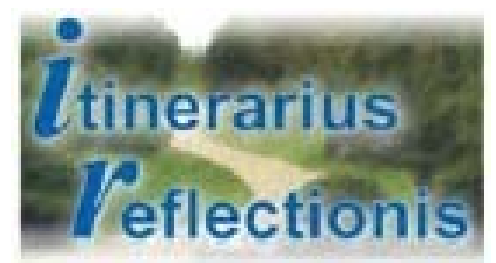

\section{Revista Eletrônica de Educação do Curso de Pedagogia do Campus Jataí da Universidade Federal de Goiás [Vol I - n.4 ] [jan/jul] [ 2008] \\ ISSN: 1807-9342}

independência que ele não possui, e presume um papel de comando que é irreconciliável com seu próprio princípio de liberdade.

A liberdade passa a ser a reprodução e a expressão do existente, por isso não é preciso reprimir a liberdade de expressão, pois a possibilidade deste espírito de se expressar é legítima, no entanto ele vai repetir o existente. Sua liberdade de expressão não desvela a realidade impregnada de ideologia - ela não consiste na crítica do existente. A cultura se transforma em ideologia, e, como afirma Adorno (1998),

a cultura só é verdadeira quando implicitamente crítica, e o espírito que se esquece disso vinga-se de si mesmo nos críticos que ele próprio cria. A crítica é um elemento inalienável da cultura, repleta de contradições e, apesar de toda sua inverdade, ainda é tão verdadeira quanto não-verdadeira é a cultura. A crítica não é injusta quando destrói esta ainda seria sua melhor qualidade - mas quando, ao desobedecer, obedece (ADORNO, 1998, p. 11).

Ao obedecer, a crítica opera na mesma lógica da barbárie, a cumplicidade entre a crítica e cultura torna-se a mesma coisa, ela legitima a cultura vigente.

Para Adorno (1998), a crítica cultural compartilha com seu objeto, o ofuscamento, e a cultura enquanto conteúdo essencial da autoconsciência não pode libertar-se dessa aparência. A idéia de consciência para ele opera na universalidade, não existe consciência singular sem a idéia de universalidade. E dentro deste contexto na qual a cultura opera, o princípio de humanidade fica suspenso nas malhas da ideologia. A noção de ideologia, diz Adorno (1998), foi transformada de um meio de conhecimento em um meio de controle do conhecimento.

Esse controle opera em diversas esferas; para ele, a cultura tornou-se ideológica também na vida privada, e se apresenta sob a aparência de importância e autonomia. É por isso que, para Adorno (1998),

'ideologia' significa sociedade enquanto aparência. Embora seja mediada pela totalidade, atrás da qual se esconde a dominação do parcial, a ideologia não é redutível pura e simplesmente a um interesse parcial; por isso, de certo modo, está em todas as suas partes à mesma distancia do centro (ADORNO, 1998, p. 21). 


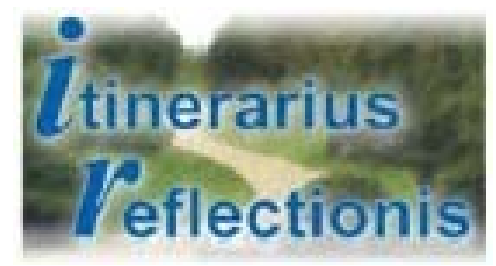

Revista Eletrônica de Educação do Curso de Pedagogia do Campus Jataí da Universidade Federal de Goiás

[Vol I - n.4 ] [jan/jul] [ 2008]

A crítica cultural foi absolvida pela ideologia imanente à cultura. Ela é fruto da própria ideologia, daí a dificuldade de transpor a aparência do real. Adorno (1998) propõe uma crítica dialética, aquela que poderia apreender a cultura em sua totalidade, em sua essência. Um método de critica dialética, que transcenda a cultura e a rede de ofuscamento em que se encontra inserida.

Neste sentido, Adorno (1998) traça uma perspectiva pouco alentadora sobre o conceito de cultura. Totalmente aderente a lógica do mercado, a cultura se converteu em uma razão instrumental. Adorno, então, buscou compreender qual a lógica que governava essa razão que se instrumentalizou, e porque o sujeito se converte a esta racionalidade. Por que o sujeito, podendo escolher, escolhe a barbárie? Porque não há liberdade de escolha, não há autonomia e a barbárie estará sempre travestida de liberdade, de realidade, de desejo, de sonho.

Todos estes aspectos da barbárie encontram respaldo nas promessas de satisfação da necessidade instaurada no bojo da indústria cultural. A cultura neste contexto transforma-se em pura ideologia.

\section{Indústria cultural e barbárie}

Adorno e Horkheimer (1991) em Dialética do Esclarecimento afirmam que

o esclarecimento tem perseguido sempre o objetivo de livrar os homens do medo e de investi-los na posição de senhores. Mas a terra totalmente esclarecida resplandece sob o signo de uma calamidade triunfal. O programa do esclarecimento era o desencantamento do mundo. Sua meta era dissolver os mitos e substituir a imaginação pelo saber (ADORNO E HORKHEIMER, 1991, p. 19).

Segundo eles, Bacon - pai da filosofia experimental - demonstrou que vários fatores, ao longo da história, impediram a interação entre entendimento humano e a natureza das coisas, transformando-os em conceitos errôneos. Bacon, segundo eles, afirma ainda, que as três invenções que provocaram a grande mudança no mundo - a imprensa, o canhão, a bússola - eram uma falácia, pois historicamente já estavam asseguradas. Ele não nega que a superioridade do 


\section{tinerarius}

Revista Eletrônica de Educação do Curso de Pedagogia

do Campus Jataí da Universidade Federal de Goiás

[Vol I - n.4 ] [jan/jul] [ 2008]

\section{0}

ISSN: 1807-9342

homem está no saber e que este saber está protegido dos tesouros que não podem comprá-lo e das vontades que sobre ele não imperam. No entanto, Bacon diz que apenas acreditamos dominar a natureza, na realidade estamos submetidos à sua necessidade e, se fôssemos nos guiar por ela na invenção, a prática estaria prevalecendo neste comando.

Adorno e Horkheimer (1991), na análise que elaboram sobre Bacon, apontam que a interação que é posta por ele entre o entendimento humano e a natureza é patriarcal, pois o entendimento que vence a superstição deve imperar sobre a natureza desencantada. O saber, neste contexto, é poder, e a técnica é a essência desse saber. As invenções citadas por Bacon como conhecimento, são para Adorno e Horkheimer (1991), instrumentos. Para eles, o que os homens querem aprender da natureza é como empregá-la para que possam dominar tanto ela quanto os homens. Neste sentido, eles afirmam que o esclarecimento eliminou sua própria autoconsciência.

Em Dialética do Esclarecimento, Adorno e Horkheimer (1991) discutem como a proposta do esclarecimento de vencer os mitos pelo saber vai sendo desintegrada ao longo da história da humanidade. O trajeto percorrido da barbárie para o esclarecimento faz o caminho inverso e do esclarecimento retorna à barbárie. Eles apontam que o desejo, como uma condição humana, atrasa o processo civilizatório e a cultura, que deveria contribuir com a formação humana, incita o desejo material. Esta mesma cultura se transforma em barbárie e, em uma dada particularidade histórica, ideologia e cultura se convertem na mesma coisa - o que é falso se converte em realidade.

Adorno desencadeia em seu pensamento a possibilidade de compreender que o homem está preso a uma razão instrumental que faz com que ele se adira à barbárie - a barbárie na concepção de Adorno não é violência e sim a própria racionalidade. Ela é um acontecimento desencadeado pelo processo histórico que só poderá ser superado pelo sujeito, na sua universalidade. Percebe-se que o mais importante para Adorno é demonstrar que a universalidade deve superar a singularidade.

É neste sentido que ele apreende o pensamento de Freud. Ele vai à psicanálise buscar, na particularidade do indivíduo, a universalidade. A psicanálise para Freud desvela a realidade e 
possibilita a reintegração do sujeito singular à universalidade, isto é, ela possibilita a este sujeito compreender e conseguir lidar com a realidade, que em sua particularidade, é falsa. Isto é o essencial para Adorno, que, no texto "La revision del psicanálise" (1966), faz uma interlocução com a psicanálise criticando os revisionistas, que, na concepção de Adorno (1966), reduzem a universalidade contida na obra de Freud.

Uma das questões importantes que, segundo Adorno, está posta em Freud é a incompletude do ser humano. Na singularidade, o indivíduo busca algo que não encontra - há uma incompletude que coloca o indivíduo na condição humana. Para Freud, diz Adorno, o problema não era que o homem fosse incompleto e sim que não seria completado. Esta é uma insatisfação que passa a ser a chave da satisfação da indústria cultural, pois esta indústria levará o sujeito a ilusão de que seu desejo pode ser satisfeito e por isto, a cada minuto, ela o alimenta.

A indústria cultural não cessa de lograr seus consumidores quanto àquilo que está continuamente a lhes prometer. A promissória sobre o prazer, emitida pelo enredo e pela encenação, é prorrogada indefinidamente: maldosamente, a promessa a que afinal se reduz o espetáculo significa que jamais chegaremos à coisa mesma, que o convidado deve se contentar com a leitura do cardápio. Ao desejo excitado por nomes e imagens cheios de brilho, o que enfim se serve é o simples encômio do cotidiano cinzento ao qual ele queria escapar (ADORNO E HORKHEIMER, 1991, p. 131-132).

Instaura-se neste contexto uma contradição - o sujeito se transforma em objeto da indústria cultural. E é aí, que a dominação encontra sua força, "o preço da dominação não é meramente a alienação dos homens com relação aos objetos dominados; com a coisificação do espírito, as próprias relações dos homens foram enfeitiçadas, inclusive as relações de cada indivíduo consigo mesmo" (ADORNO E HORKHEIMER, 1991, p. 40)

Percebe-se, neste sentido, o poder da dominação ao qual o sujeito se encontra submetido, pois a indústria cultural leva-o a acreditar em uma promessa de felicidade que será satisfeita, por isso ela alimenta o tempo todo o seu desejo. A indústria terá sempre um produto para este indivíduo, e buscará suprir seus diferentes desejos. Antes que ele perceba que o desejo não foi realizado, o produto será reposto. 


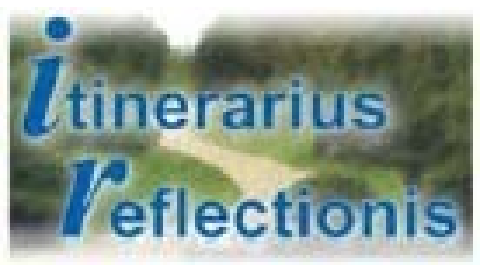

Revista Eletrônica de Educação do Curso de Pedagogia do Campus Jataí da Universidade Federal de Goiás

[Vol I - n.4 ] [jan/jul] [ 2008]

ISSN: 1807-9342

Segundo Adorno e Horkheimer (1991), a partir do momento em que as mercadorias perderam suas qualidades econômicas e mantiveram o caráter fetiche, elas se espalharam pela vida da sociedade em todos os aspectos. Eles acreditavam que as produções em massa e da cultura por ela criada servem para inculcar no indivíduo os comportamentos normalizados, isto é, a cultura de massa inculca a naturalização dos comportamentos humanos, dentre eles, a barbárie.

Quando a ideologia se converte em cultura, o indivíduo, cuja personalidade é regida pela razão instrumental, se adere à realidade que em sua essência é falsa. Neste sentido, Adorno diz que a cultura afirma os desejos que produz, sendo assim, ela é a base da personalidade que se adere. A personalidade só é mediadora na cultura que lhe é afirmativa, a cultura afirma o real, no entanto, o fato de que seja real não significa que seja verdade. A realidade que se apresenta nesta sociedade é que a mercadoria esta ali para me servir, isto sim, é real.

Tal adesão da personalidade leva ao que Adorno e Horkheimer (1991) chamaram de mimese cultural, uma identificação completa do consumidor com a mercadoria.

\footnotetext{
As mais íntimas reações das pessoas estão tão completamente reificadas para elas próprias que a idéia de algo peculiar a elas só perdura na mais extrema abstração: personality significa para elas pouco mais do que possuir dentes deslumbradamente brancos e estar livres do suor nas axilas e das emoções. Eis aí o triunfo da publicidade na indústria cultural, a mimese compulsiva dos consumidores, pela qual se identificam às mercadorias culturais que eles, ao mesmo tempo, decifram muito bem" (ADORNO E HORKHEIMER, 1991, P. 156).
}

Adorno (1987) afirma que a indústria cultural especula sobre o estado de consciência e inconsciência de milhões de pessoas às quais ela se dirige; as massas são um elemento secundário da indústria cultural. É neste sentido que ele afirma que "o consumidor não é rei, como a indústria gostaria de fazer crer, ele não é o sujeito dessa indústria, mas seu objeto" (Adorno, 1987, p. 288). Dentro desta lógica, o que é importante na indústria cultural não é o produto ela que produz, mas a lógica expressa naquele objeto. Independente do tipo de produto, ele sempre terá a mesma lógica. Para ele, a lógica da indústria cultural, que é a instrumentalização, é incompatível com a lógica da autonomia. 


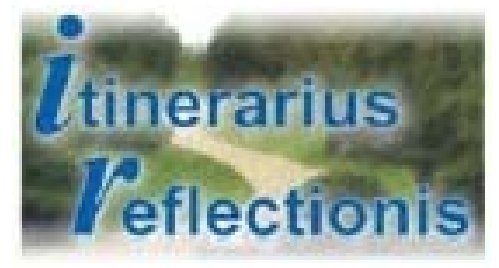

Revista Eletrônica de Educação do Curso de Pedagogia do Campus Jataí da Universidade Federal de Goiás

[Vol I - n.4 ] [jan/jul] [ 2008]

Adorno (1987) investe contra a industria cultural da mesma forma que ela logra a sociedade. $\mathrm{Na}$ verdade, nunca como agora se prometeu tanto, em nenhuma particularidade histórica a realidade se converteu tanto em verdade. A realidade se converte em ideologia e a ideologia se transforma em cultura, no entanto, elas não se conciliam, pois se não, a indústria cultural não precisaria alimentar o mercado com diferenciações a cada momento.

A grande contribuição de Adorno, sua particularidade que se universalizou, foi desvelar a questão da racionalidade instrumental. Que razão é esta que, podendo proporcionar um homem ontológico, proporciona apenas indivíduos reificados? Adorno não apresenta uma saída em sua teoria, ele possibilita a compreensão da realidade na forma em que ela se apresenta, a saber, ideologizada, e instaura a possibilidade de buscar uma outra razão. O antídoto, para Adorno, é a autonomia e a razão crítica, pois, a racionalidade crítica contém a barbárie mas a consciência na barbárie não contém a racionalidade.

A autonomia proposta por ele seria de se pensar a indústria cultural de outra maneira que não seja a maneira como ela se pensa. Mesmo assim as chances são mínimas, pois, “a indústria cultural derruba a objeção que lhe é feita com a mesma facilidade com que derruba a objeção ao mundo que ela duplica com imparcialidade. Só há duas opções: participar ou omitirse" (ADORNO E HORKHEIMER, 1991, p.138)

Adorno não aponta uma saída para esta tensão que se instaura historicamente, mas em diferentes momentos ele nos diz que o sujeito autônomo teria a consciência crítica para compreender a realidade que se apresenta, esta possibilidade se apresenta durante a formação cultural do indivíduo. Infelizmente percebe-se que, como ele mesmo apontou, é preciso elaborar uma crítica dialética da formação cultural que se apresenta na realidade ideologizante desta sociedade. A racionalidade nesta realidade se fetichisa de tal forma que se concilia com a indústria cultural, transformando formação cultural em semicultura.

\section{Adorno e a teoria da semicultura}




\section{tinerarius}

Neste sentido, compreende-se porque, para Adorno (2002), a formação cultural, se encontra em crise. São inúmeros os aspectos, formativos ou não, inseridos no cotidiano dos indivíduos e que bloqueiam as possibilidades de uma formação cultural verdadeira, que, para Adorno, está calcada na formação de um indivíduo autônomo. Para ele, os sintomas desta crise são observados por toda parte, e muitas vezes as reformas pedagógicas isoladas, propostas pelas políticas educacionais, ao invés de trazer contribuições substanciais, podem até reforçar a crise, pois, segundo ele, abrandam as necessárias exigências a serem feitas aos que devem ser educados. Para Adorno (2002), as investigações sobre os fatores sociais que interferem na formação cultural e que poderiam contribuir com sua compreensão são insuficientes, e os primeiros momentos a serem compreendidos deveriam ser os que compõem a totalidade social da formação cultural.

Assim, afirma Adorno (2002), a formação cultural se converte em uma semiformação socializada. Aprisionada nas malhas da socialização, a semiformação passou a ser a forma dominante da consciência atual e, por isso, exige uma teoria que não considere a idéia de cultura de forma sagrada, o que, para ele, estaria reforçando a semiformação. A formação, para Adorno, nada mais é que a cultura tomada pelo lado de sua apropriação subjetiva.

Para Adorno (2002), o conceito de formação se emancipou com a burguesia. A sua realização deveria corresponder a uma sociedade de seres livres e iguais, mas, segundo ele, desviou-se de seus fins e de sua função real, a formação cultural deveria ser aquela que dissesse respeito ao indivíduo livre e radicado em sua própria consciência, no entanto "os dominantes monopolizaram a formação cultural numa sociedade formalmente vazia. A desumanização implantada pelo processo capitalista de produção negou aos trabalhadores todos os pressupostos para a formação e, acima de tudo, o ócio" (ADORNO, 2002, p.4).

Adorno (2002) faz alusão aos primeiros proletários, citados em O Capital, cujas pressões das condições de vida, o prolongamento da jornada de trabalho, o salário deplorável, os mantiveram excluídos da nova situação. Ele ressalta ainda que, no tocante ao fundamento econômico das relações, não houve mudanças e nem quanto aos limites inicialmente propostos 


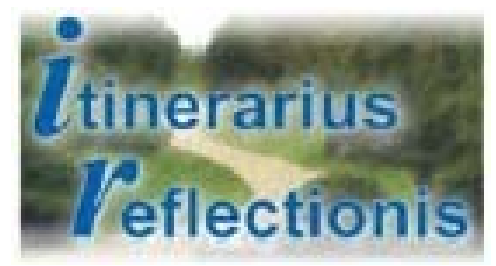

Revista Eletrônica de Educação do Curso de Pedagogia
do Campus Jataí da Universidade Federal de Goiás
[Vol I - n.4 ] [jan/jul] [ 2008]
ISSN: 1807-9342

para a formação cultural; no entanto, a ideologia se transformou de forma radical. Por inúmeros canais, afirma Adorno, se fornece às massas bens de formação cultural. Uma formação que é substancialmente ideológica e que chega a massa de excluídos de modo irrefletido. Neste sentido, ele acredita que a formação cultural tradicional é o único conceito que serve de antítese a semiformação socializada. Segundo ele,

no clima da semiformação, os conteúdos objetivos, coisificados e com caráter de mercadoria da formação cultural, perduram à custa de seu conteúdo de verdade e de suas relações vivas com o sujeito vivo, o qual, de certo modo, corresponde a sua definição. (...), contudo a indústria cultural, em sua dimensão mais ampla - tudo o que o jargão específico classifica como mídia -, perpetua essa situação, explorando-a, e se assumindo como cultura em consonância com a integração (...) ( ADORNO, 2002, p.7).

Formação, para Adorno, tem como condições a autonomia e a liberdade, mas dentro das condições determinadas pela indústria cultural ${ }^{2}$, o indivíduo é privado de uma consciência crítica e, portanto da possibilidade de desenvolvimento desta autonomia. Conforme as condições estabelecidas ao indivíduo para que essa autonomia ocorra, a formação fica comprometida.

Ao analisar as possibilidades para que uma formação fosse possível, Adorno (2002) salienta seu desenvolvimento no escopo da sociedade, e afirma que as reformas escolares descartaram a antiquada autoridade, antes presente nas relações familiares. Essa autoridade é parte de um processo de formação e enfraquece mais ainda a dedicação e o aprofundamento íntimo do espiritual, a que estava vinculada uma liberdade. Segundo ele, aspectos desta educação, mesmo contendo uma certa mecanicidade, possibilitavam ao intelecto e ao espírito uma parte do alimento de que se nutre a formação. A formação cultural, para o autor, requeria proteção diante das atrações do mundo exterior, certas ponderações com o sujeito singular, e até lacunas de socialização.

Uma outra questão presente no pensamento de Adorno (2002), sobre as condições de formação, diz respeito à carência de imagens a que o individuo está sujeito.

\footnotetext{
${ }^{2}$ Segundo Adorno (1987, p.291), os políticos da cultura bem como alguns sociólogos acreditam que, por meio da indústria cultural, podem propiciar uma formação da consciência de seus consumidores, mas, diz Adorno, a indústria cultural é importante como característica do espírito hoje dominante e em função disso não deveria ser subestimada.
} 


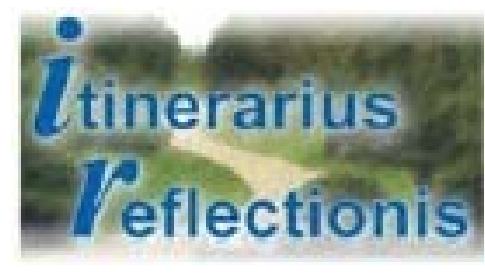

\author{
Revista Eletrônica de Educação do Curso de Pedagogia \\ do Campus Jataí da Universidade Federal de Goiás \\ [Vol I - n.4 ] [jan/jul] [ 2008] \\ ISSN: 1807-9342
}

A vida, modelada até suas últimas ramificações pelo princípio da equivalência, se esgota na reprodução de si mesma, na reiteração do sistema, e suas exigências se descarregam sobre os indivíduos tão dura e despoticamente, que cada um deles não pode se manter firme contra elas como condutor de sua vida própria, nem incorporá-las como algo específico da condição humana. Daí que a existência desconsolada, a alma, que não atingiu seu direito divino na vida, tenha necessidade de substituir as perdidas imagens e formas através da semiformação (ADORNO, 2002, p. 10).

Este despreparo favorece a mitologização, isto é, a popularização a que estrelas de cinema ou canções de sucesso proporcionam ao consumidor, que para Adorno (2002), são aspectos de uma semiformação. Adorno sempre empreendeu grandes debates frente a essa realidade cotidiana do homem no mundo das imagens, entre elas, apresenta a categoria da indústria cultural que, diante do domínio do capital, cobre a realidade com fina membrana ideológica porém intransponível para aqueles que não atingem uma autonomia.

Percebe-se que as teias desta indústria estão traçadas em vários ramos e Adorno (2002), neste debate sobre semiformação, aponta desde os clássicos da filosofia - que a indústria cultural, em um discurso de acessibilidade ao grande público, edita edições de bolso, as quais para Adorno, contraditoriamente, trazem, como conseqüência, confusão e obscurantismo - até a decadência do gosto musical causado pela regressão da audição ${ }^{3}$ com a indústria fonográfica. "Confiante na ignorância, o mercado cultural dela se nutre e a ela reproduz e reforça. A alegre e despreocupada expansão da formação cultural, nas condições vigentes, é, de modo imediato, sua própria aniquilação" (ADORNO, 2002, p. 12).

A análise que Adorno (2002) elabora sobre a semiformação põe o indivíduo no centro de uma estrutura insustentável, ele é o consumidor de uma cultura produzida, em sua objetividade, sob medida; cuja dimensão dos conteúdos por ele consumidos foram nutridos, em sua própria ignorância. Ele é, neste contexto, o semiculto, aquele que, se dedica à conservação de si mesmo. Com características narcíseas ele se julga o melhor, aquele que tudo conhece, sabe e faz e sob influência da semiformação tornou-se um conformista que, como bem caracterizado por

${ }^{3}$ Ver sobre este assunto: ADORNO T. W. "O fetichismo na música e a regressão da audição", in: Os Pensadores, São Paulo, Nova Cultural, 2000. 


\section{tinerarius}

\section{p}

ISSN: 1807-9342

Adorno, ao mesmo tempo em que se apossa fetichisticamente dos bens culturais, está sempre na iminência de destruí-los.

Como fruto de uma inconsciência, gerada pela semiformação, essa destruição se apresenta no contexto do próprio conhecimento. Quanto mais o indivíduo se apropria de uma semiformação, mais ela se instaura na esfera da consciência, como barbárie. Neste sentido, Adorno (2002) afirma que a única possibilidade de sobrevivência que resta a cultura é a autoreflexão crítica sobre a semiformação, em que se converteu.

Dado ao exposto, ao se percorrer as idéias de Adorno, como fez Martin Jay (1998), pode-se deparar com uma análise altamente crítica que tem por finalidade desvelar aos olhos dos indivíduos a realidade desfigurada que a ele se apresenta, mas que, em determinada particularidade, se apresenta travestida de luxo, brilho, encanto, desejo, necessidade. Adorno procurou mostrar que somente uma consciência autônoma seria capaz de perceber a ideologia contida na indústria cultural, bem como que a avalanche de informações por ela transmitida não é esclarecimento. Na realidade, instaura-se o obscurantismo, o fascismo, a barbárie.

Dentre as questões debatidas por Adorno percebe-se que a busca pela universalidade regia sua linha de pensamento. Somente um sujeito universal, autônomo, estaria livre do fascismo, da barbárie - ele buscava a condição humana, pois somente quando se instaura a condição humana se instaura a civilização, a cultura, a condição de socialização.

É neste sentido, que Martin Jay (1988) faz uma importante consideração a respeito da teoria exposta por Adorno e diz que é impossível - dada a história por ele apresentada - que se chegue a uma saída para esta tensão. Adorno deixou instaurada a possibilidade de um caminho a ser percorrido - o descortinamento da realidade só será apreendido por uma consciência autônoma que em sua origem compreende o desconforto instaurado pela cultura ideologizada - e chamou a atenção para que não ocorresse a fetichização da autonomia, pois, desta forma, isso poderia se constituir um obstáculo à realização de sua utopia. É possível pensar, então, que não há indivíduo livre de risco nesta sociedade, a saber, um campo arraigado de verdades falsas, mas, 


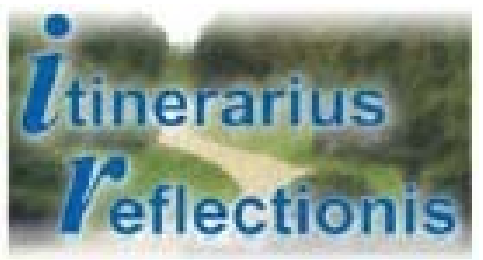

Revista Eletrônica de Educação do Curso de Pedagogia do Campus Jataí da Universidade Federal de Goiás

[Vol I - n.4 ] [jan/jul] [ 2008]

ISSN: $1807-9342$

se em uma dada particularidade, a semiformação se converter em formação cultural, instaura-se a possibilidade desta utopia se efetivar.

\section{Bibliografia}

ADORNO, Theodor $\mathrm{W}$. Temas básicos da sociologia. São Paulo: Cultrix: Editora da Universidade de São Paulo, 1973.

. A indústria cultural. In: COHN, Gabriel. Comunicação e indústria cultural. 5 ed. São Paulo, T.A. Queiroz Editor, 1987.

. Teoria da Semicultura. Tradução de Newton Ramos-de-Oliveira, Bruno Pucci e Cláudia B. M. de Abreu. In: Educação e Sociedade: revista quadrimestral de ciência da educação, ano XVII, no 56, Campinas: Editora Papirus, dez/ 1996: 388-411. Disponível em: <http://planeta.clix.pt/Adorno/>. Acesso em: 29 de abril. 2002.

. Crítica cultural e sociedade. In: Prismas. São Paulo: Ática, 1998. p. 7-26.

. La revisiom del psicoanalisis. In: Sociológica. Taurus. Buenos Aires, 1966.

Editora, 1991.

e Horkheimer, Max. Dialética do Esclarecimento. Rio de Janeiro: Jorge Zahar

JAY, Martin. As idéias de Adorno. Tradução Abdail Ubirajara Sobral. São Paulo: Cultrix: Editora da Universidade de São Paulo, 1988. 